\title{
Hybrid preference assessment for tourism research using solicited and unsolicited opinions: an application in rural tourism
}

\author{
Evaluación de preferencias híbridas para la investigación turística utilizando opiniones solicitadas y no solicitadas: \\ una aplicación en turismo rural
}

Manuel Ángel Fernández-Gámez

University of Málaga, Department of Finance and Accounting, Spain, mangel@uma.es

Elias Bendodo-Benasayag

University of Málaga, PhD Program in Tourism, Spain, ebendodo@malaga.eu

José Ramón Sánchez-Serrano

University of Málaga, Department of Finance and Accounting, Spain, joseramonsanchez@uma.es

Maria Helena Pestana

ISCTE-IUL, Lisbon, Portugal, helena.pestana@iscte-iul.pt

\begin{abstract}
Social media analysis is a powerful tool for tourism research that, at a relatively low cost, can be used to manage and process large datasets of comments, ratings, and shares from different online communities. However, the heterogeneous nature of unsolicited opinions, the complexity of natural language assessment, and differences in the characteristics of social-data sources hinder the accurate assessment of preferences. Likewise, the use of solicited data sources, such as direct polling, is typically resource-intensive, time-consuming, and geographically limited. We analyze a hybrid approach that combines active polling with passive social media analysis to rate tourist experience. To this end, we present a novel multiple criteria decision analysis model for preference-extraction from solicited and unsolicited data. The proposed approach can significantly reduce the number of polls required to accurately assess the preferences of a community, especially when surveying rural destinations, which are sparsely populated geographic areas situated outside cities and towns.
\end{abstract}

Keywords: Social media analysis, online communities, tourists' preferences, rural tourism, multiple criteria decision analysis.

\section{Resumen}

El análisis de las redes sociales es una herramienta poderosa para la investigación turística que se puede utilizar para administrar y procesar grandes conjuntos de datos de comentarios, calificaciones y acciones de diferentes comunidades en línea. Sin embargo, la naturaleza heterogénea de las opiniones no solicitadas, la complejidad de la evaluación del lenguaje natural y las diferencias en las características de las fuentes de datos sociales dificultan la evaluación precisa de las preferencias. Analizamos un enfoque híbrido que combina encuestas activas con análisis pasivos de redes sociales para calificar la experiencia turística. Con este fin, presentamos un nuevo modelo de análisis de decisión de criterios múltiples para la extracción de preferencias de datos solicitados y no solicitados. El enfoque propuesto puede reducir significativamente el número de encuestas requeridas para evaluar con precisión las preferencias de una comunidad, especialmente al encuestar a destinos rurales, que son áreas geográficas escasamente pobladas situadas fuera de las ciudades y pueblos.

Palabras clave: Análisis de redes sociales, comunidades en línea, preferencias de los turistas, turismo rural, análisis de decisión de criterios múltiples.

\section{Introduction}

There is increasing interest in understanding tourists' preferences and viewpoints, given that this information is useful for tourism business research (Brown, 2015; Liutikas, 2017). Thus, there is a need for new preference assessment strategies that directly gather information from tourists. Social media is one of the main and growing sources of tourism-related information (Ayeh, Au \& Law, 2013; Boley, Jordan, Kline \& Knollenberg, 2018; Munar \& Jacobsen, 2014; Xiang, Du, Ma \& Fan, 2017).

Recently, social network analysis (SNA) has become a dominant tool for decision making and business research (Batrinca \& Treleaven, 2014; Fan \& Gordon, 2013; Ordenes et al., 2017). Social network analysis has been defined as a strategy for investigating social structures that combines sociology theory, information theory, and mathematical analysis (Otte \&
Rousseau, 2002). Similarly, social media analysis (SMA) can be interpreted as a specialized form of SNA that analyses media content generated by users of social media platforms as well as the relationships between this media content within the network of users.

Furthermore, SNA is a powerful tool for tourism research that, at a relatively low cost, can be used to manage and process large datasets of comments, ratings, and shares from different online communities (Brown, 2015; Liu \& Liang, 2016; Monterrubio, 2017; Otte \& Rousseau, 2002; Schroeder, Pennington-Gray, Kim \& Liu-Lastres, 2018; Zeng \& Gerritsen, 2014). However, the heterogeneous nature of unsolicited opinions, the complexity of natural language assessment, and differences in the characteristics of the social-data sources hinder the accurate assessment of preferences (Peláez, Cabrera \& Vargas, 2018; Rai et al., 2018; Sandberg, Jaradat \& Dokoohaki, 2016). 
However, the use of solicited data sources, such as direct polling, is typically the preferred approach to assess individual viewpoints. In this case, questionnaires can be constructed such that individual preferences can be assessed in detail, whereas SNA requires the assessment of many conversations to compensate for the little information provided by each individual opinion. Nevertheless, direct polling is often resource-intensive, time-consuming, and geographically limited. Difficulties in direct polling in tourism research are particularly marked when surveying rural destinations, which are sparsely populated geographic areas situated outside cities and towns (Kelliher, Reinl, Johnson \& Joppe, 2018).

We analyze a hybrid approach for preference assessment that combines active polling with passive SNA to build a unified preference metric for tourism research. To this end, we present a novel multiple criteria decision analysis (MCDA) model for preference-extraction from solicited and unsolicited data. We also present a real-world application of the proposed MCDA model for the assessment of preferences in rural destinations.

\section{Materials and methods}

Many decision-making scenarios involve choices based on information provided by peers based on their previous experience. The relationships between the perceived information and final decisions are very complex, and thus difficult to model and predict. To overcome these difficulties, previous studies have proposed MCDA methods to model the decision process. In MCDA, criteria are assessed in relation to a target. Specifically, MCDA identifies the relevance of the criteria that lead to choosing one of the target alternatives (Fernández, Bendodo, Sánchez \& Cabrera, 2017).

In this regard, we address the issue of rating various rural destinations in Málaga Province (Andalusia, Spain). According to official sources, rural tourism in Málaga Province has increased in the past decade (Turismo y Planificación Costa del Sol S.L.U., 2017). The reasons for this increase are not well documented; however, previous reports suggest that one of the key factors is improvements in public transport and road systems that lead to small towns. On the other hand, there has also been an increase in the number of comments on rural destinations in Málaga in social media. This study addresses six of these destinations, which account for more than $80 \%$ of rural accommodation in this province: Ronda, Antequera, Frigiliana, Alhaurín el Grande, Álora, and Coín.

\subsection{Define the social choice problem by identifying plausible} alternatives

The first step in the proposed model is to establish a set of comparable alternatives that comprise the target of the MCDA process. Two alternatives are "comparable" if the majority of the study population of individuals consider them to be plausible candidates under the same conditions (e.g. car rental agencies in a given airport, hotels located near the same tourism attraction, neighbouring beaches in a given city, and cities within the same region).

The set of alternatives defines the social choice problem for the proposed MCDA model and can be formally represented as a set:

$$
A=\left\{a_{1}, a_{2}, \cdots, a_{k}\right\}
$$

where $A$ represents the set of $k$ comparable alternatives $a_{i}$. In this study, set $A$ corresponds to:

$$
A=\left\{\begin{array}{c}
\text { Ronda, } \\
\text { Antequera, } \\
\text { Frigiliana, } \\
\text { Alhaurín el Grande, } \\
\text { Álora, } \\
\text { Coín }
\end{array}\right\}
$$

\subsection{Identify the criteria that drive decisions}

The second step identifies the most relevant criteria when choosing one of the alternatives in set $A$. In the proposed method, the inclusion requirements for each criterion are as follows:

\section{All the alternatives in A must be describable by the criterion.}

2. The profile of the alternative described by the criterion must be quantifiable.

Formally, each alternative $a_{i} \in A$ has a profile of $x^{a}=$ $\left(x_{1}^{a}, x_{2}^{a}, \ldots, x_{n}^{a}\right) \in \mathbb{R}^{n}$, where $x_{i}^{a}$ is a partial assessment of $a$ in relation to criterion $c_{j}$. From $x^{a}$ it is possible to estimate an overall measure $M\left(x^{a}\right)$ for each alternative using an aggregation operator $M: \mathbb{R}^{n} \rightarrow \mathbb{R}$ (Peláez et al., 2018).

The following criteria were chosen for this study:

1. Accommodation.

2. Public infrastructures.

3. Cultural highlights.

4. Natural attractions.

\subsection{Assess the criteria}

Typical summarization approaches, such as the arithmetic mean, are not suitable for identifying the relevance of decision criteria when there are many opinions originating from multiple individuals with heterogeneous points of view. Therefore, an aggregation procedure is needed (La Red, Doña, Peláez \& Fernández, 2011). Aggregation is the mechanism for finding a value that represents the opinions of multiple individuals on a given alternative with "good enough" quality.

The proposed model uses a robust eigenvector-based pairwise voting approach that does not violate democracy when considering multiple decision makers (Vargas, 2016). The researchers consulted 16 experts in tourism from local universities and state-run agencies in the province of Málaga. Each expert ranked the set of criteria such that $x_{i}>x_{j}$ means " $x_{i}$ is preferred to $x_{j}$ ". Subsequently, a pairwise voting matrix $X(\phi)$ was constructed: 


$$
X(\phi)=\left[\begin{array}{cccc}
1 & \frac{v_{12}(\phi)}{v_{21}(\phi)} & \cdots & \frac{v_{1 n}(\phi)}{v_{n 1}(\phi)} \\
\frac{v_{21}(\phi)}{v_{12}(\phi)} & 1 & \cdots & \frac{v_{2 n}(\phi)}{v_{n 2}(\phi)} \\
\vdots & \vdots & \ddots & \vdots \\
\frac{v_{n 1}(\phi)}{v_{1 n}(\phi)} & \frac{v_{n 2}(\phi)}{v_{2 n}(\phi)} & \cdots & 1
\end{array}\right]
$$

where $\frac{v_{i j}(\phi)}{v_{j i}(\phi)}$ represents the voting ratio between the number of voters who preferred alternative $i$ to alternative $j$. Finally, the normalized principal eigenvector of $X(\phi)$ was used to represent the weights of the criteria, as follows:

$$
W(X)=\left[\begin{array}{l}
0.1429 \\
0.1905 \\
0.2857 \\
0.3810
\end{array}\right]
$$

\subsection{Assessment of communications from social media platforms}

Automated procedures can be used to obtain communications from open or private sources, such as Twitter or Facebook APIs. We obtained relevant communications related to rural tourism in Málaga province using the capture $\rightarrow$ extraction $\rightarrow$ semantic analysis approach, which has proven useful for similar tasks (Peláez et al., 2018). Firstly, communications were acquired from social networks using passive (API) or active (scraping) methods and stored in a data pool. Secondly, a subset of communications related to rural tourism was extracted from the data pool by query-based contextualization. Finally, the topic of the communication related to the criteria was determined using automatic natural language analysis techniques.

Communications were classified into one of four categories corresponding to the criteria. Furthermore, each communication was evaluated as a "good" or a "bad" experience. For example:
- "I would love to go to a little house by Frigiliana, combining the rural and the beach for this season" $\rightarrow$ GOOD ACCOMMODATION at FRIGILIANA.

- "Huge traffic jam in the road to Coín, ruining my vacations" $\rightarrow$ BAD PUBLIC INFRASTRUCTURES at COÍN.

The final rating of the destination acquired from the evaluated communications was the weighted aggregated mean of the profile set, using the $W(X)$ vector for category weights (see Eq. 4 ), and considering a GOOD experience as a positive value and a BAD experience as a negative value.

\subsection{Assessment of solicited opinions}

The study survey was conducted daily from July 1,2019 , to 28 September 2019, thus covering the summer holiday period in Spain. The interviewers used a purpose-built digital polling system. A total of 77 tourists were surveyed after returning by bus from rural vacations to the city of Málaga (the capital of Málaga Province). Inclusion criteria were: being 18 years old or older and having stayed overnight in at least one of the studied destinations.

\subsection{Questionnaire design}

The variables analyzed in the survey were: gender, age, educational level, country of residence, and length of stay. Tourists who participated were asked to rate the visited destination using a 7-point Likert-type scale. The Likert-type scale ranged from completely dissatisfied to completely satisfied (Andriotis, Agiomirgianakis \& Mihiotis, 2008; Vagias, 2006; Zatori, Smith \& Puczko, 2018).

\section{Results}

We acquired a total of 77 direct polls and 403 unsolicited comments using SNA. Table 1 shows the distribution of data entries and Figure 1 shows the proportion of solicited to unsolicited data.

Table 1 - Distribution of data entries

\begin{tabular}{|l|c|c|c|c|}
\hline \multicolumn{1}{|c|}{ Source } & Frequency & Percentage & Valid percentage & Cumulative percentage \\
\hline Solicited & 77 & 16.0 & 16.0 & 16.0 \\
\hline Unsolicited & 403 & 84.0 & 84.0 & 100.0 \\
\hline Total & 480 & 100.0 & 100.0 & \\
\hline
\end{tabular}

Figure 1 - The proportion of solicited to unsolicited data

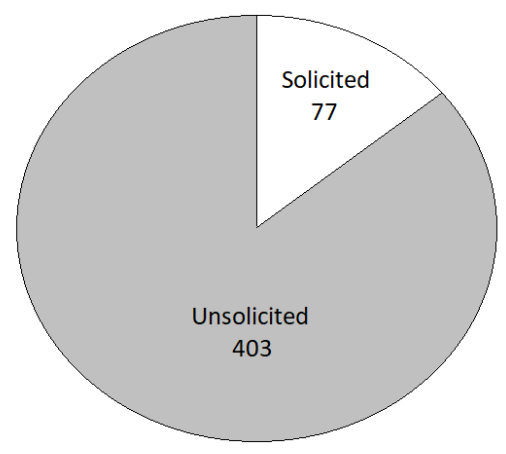


Due to the nature of unsolicited opinions, it was not possible to determine the exact age of the individuals who provided opinions on social networks. On the other hand, the mean age of the tourists who contributed to the survey was 39.97 years. Table 2 shows the descriptive statistics of the age of the participants.

Table 2 - Descriptive statistics of the age of the participants per data source

\begin{tabular}{|l|c|c|c|c|c|}
\hline \multicolumn{1}{|c|}{ Source } & N & Min & Max & Mean & SD \\
\hline Solicited & 77 & 18 & 82 & 39.97 & 13.77 \\
\hline Unsolicited & 403 & - & - & - & - \\
\hline
\end{tabular}

The country of origin for unsolicited communications was inferred using the language used in the post. Most of the participants were Spaniards, comprising $77.9 \%$ of the unsolicited sources and $66.5 \%$ of the solicited sources. Table 3 shows a cross-tabulation of source and country of origin.

Table 3 - Cross-tabulation of source vs country of origin

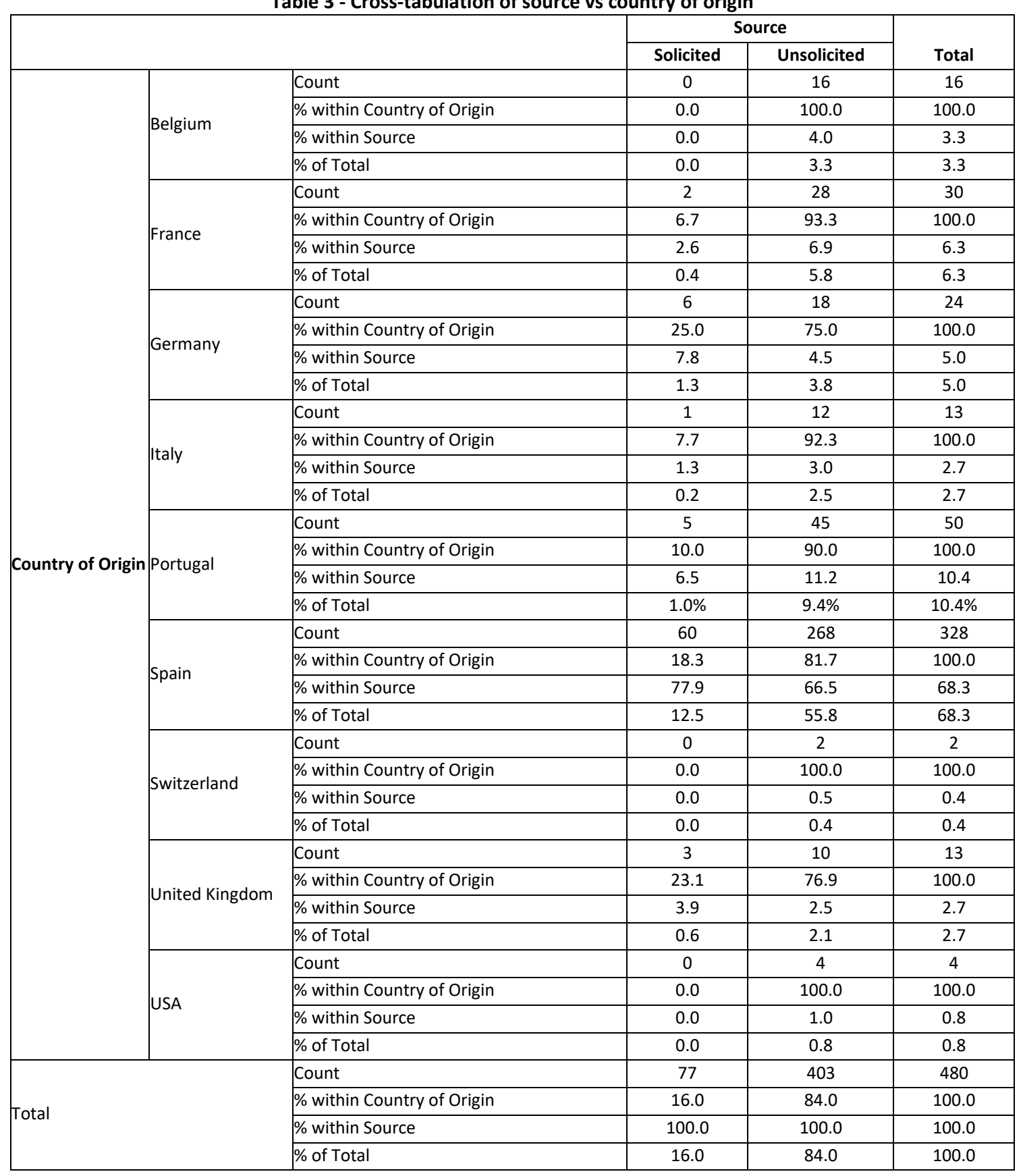


The gender of the posters of unsolicited communications was inferred using the reported public information in the social networks. The gender of the participants was evenly distributed across sources and destinations. Table 4 shows a crosstabulation of the source and gender of the participants.

Table 4 - Cross-tabulation of source vs gender

\begin{tabular}{|c|c|c|c|c|c|}
\hline & & & & & Tatal \\
\hline & & & Female & Male & Total \\
\hline & & Count & 45 & 32 & 77 \\
\hline & Solicited & $\%$ within Source type & 58.4 & 41.6 & 100.0 \\
\hline & pomcicen & $\%$ within Gender & 17.9 & 14.0 & 16.0 \\
\hline caunso & & $\%$ of Total & 9.4 & 6.7 & 16.0 \\
\hline 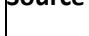 & & Count & 207 & 196 & 403 \\
\hline & Huncolicitod & $\%$ within Source type & 51.4 & 48.6 & 100.0 \\
\hline & ש & $\%$ within Gender & 82.1 & 86.0 & 84.0 \\
\hline & & $\%$ of Total & 43.1 & 40.8 & 84.0 \\
\hline & & Count & 252 & 228 & 480 \\
\hline & & $\%$ within Source type & 52.5 & 47.5 & 100.0 \\
\hline & & $\%$ within Gender & 100.0 & 100.0 & 100.0 \\
\hline & & $\%$ of Total & 52.5 & 47.5 & 100.0 \\
\hline
\end{tabular}

According to solicited and unsolicited sources, the most preferred destination was Frigiliana, which comprised $32.5 \%$ of the solicited sources and $34.7 \%$ of the unsolicited sources. Table 5 shows a cross-tabulation of source vs preferred destinations.

Table 5 - Cross-tabulation of source vs preferred destination

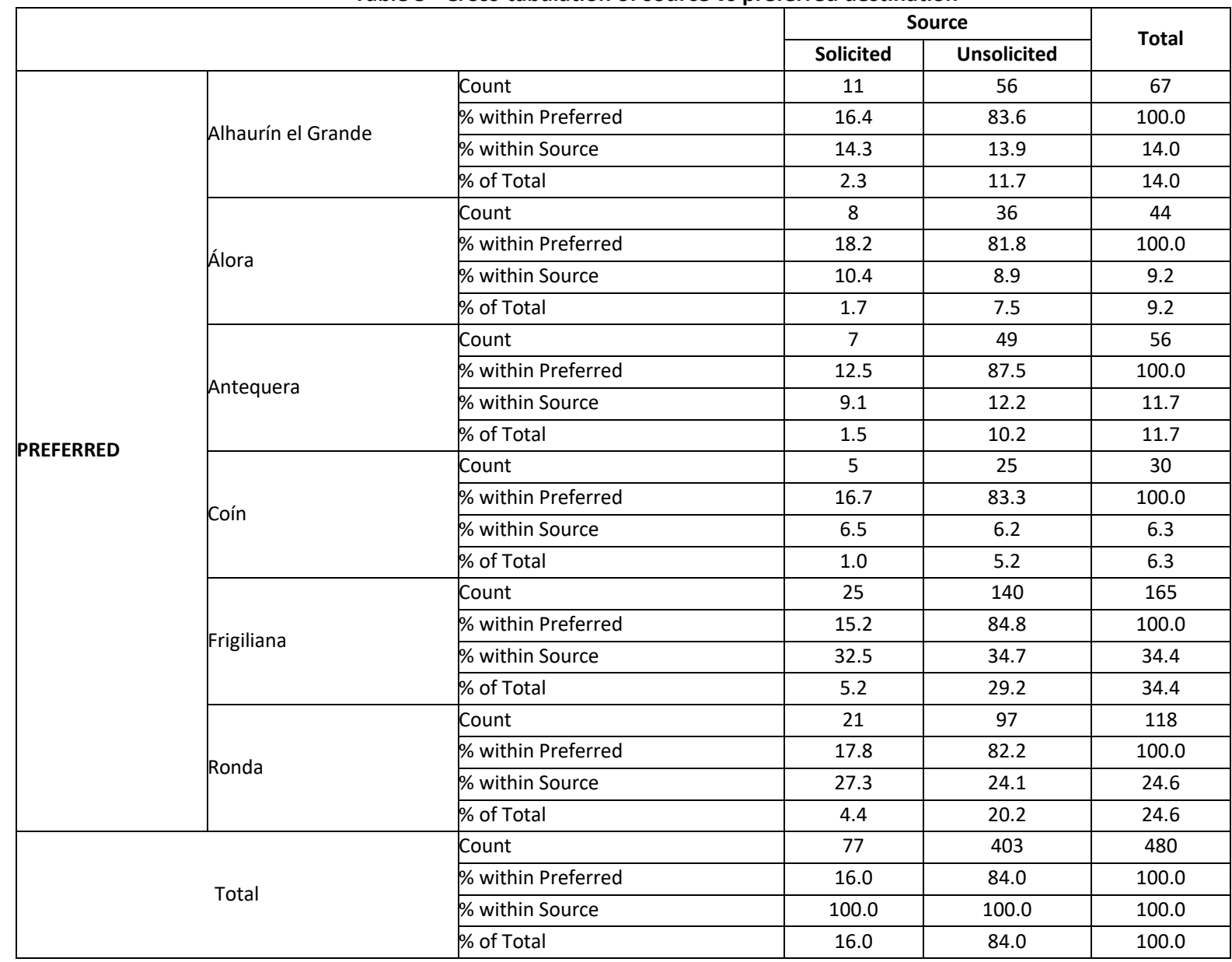

Some of the test participants reported visiting more than one of the studied destinations. Therefore, 118 ratings were obtained from 77 participants. The highes-rated destination from direct polling was Antequera (6.11) followed by Ronda (6.00). Table 6 shows the descriptive statistics of the ratings obtained from solicited opinions. 
Table 6 - Descriptive statistics of the destination ratings obtained from solicited opinions

\begin{tabular}{|l|c|c|c|c|c|}
\hline & N & Min & Max & Mean & SD \\
\hline Score Ronda & 25 & 4 & 7 & 6.00 & 1.225 \\
\hline Score Antequera & 9 & 3 & 7 & 6.11 & 1.364 \\
\hline Score Frigiliana & 39 & 2 & 7 & 5.62 & 1.498 \\
\hline Score Alhaurín el Grande & 20 & 3 & 7 & 4.95 & 1.468 \\
\hline Score Álora & 17 & 1 & 7 & 4.71 & 1.863 \\
\hline Score Coín & 8 & 3 & 7 & 5.88 & 1.458 \\
\hline Valid N & 118 & & & & \\
\hline
\end{tabular}

Correlation analysis found a strong monotonic association between the ratings obtained from solicited and unsolicited sources (Spearman's rho $=0.928, p=0.008$ ). Moreover, Linear Regression Analysis found a strong linear relationship $\left(R^{2}=\right.$
0.788). Table 7 shows the results of Spearman's correlation analysis and Figure 2 shows a scatter plot of the normalized scores.

Table 7 - Correlation between the scores obtained from solicited and unsolicited sources

\begin{tabular}{|c|c|c|c|c|}
\hline & & & Solicited & Unsolicited \\
\hline \multirow{6}{*}{ Spearman's rho } & \multirow{3}{*}{ Solicited } & Correlation Coefficient & 1.000 & $0.928 * *$ \\
\hline & & Sig. (2-tailed) & . & 0.008 \\
\hline & & $\mathrm{N}$ & 6 & 6 \\
\hline & \multirow{3}{*}{ Unsolicited } & Correlation Coefficient & $0.928^{* *}$ & 1.000 \\
\hline & & Sig. (2-tailed) & 0.008 & . \\
\hline & & $\mathrm{N}$ & 6 & 6 \\
\hline
\end{tabular}

Figure 2 - Scatter plot of the ratings of the studied destinations obtained from solicited vs unsolicited data

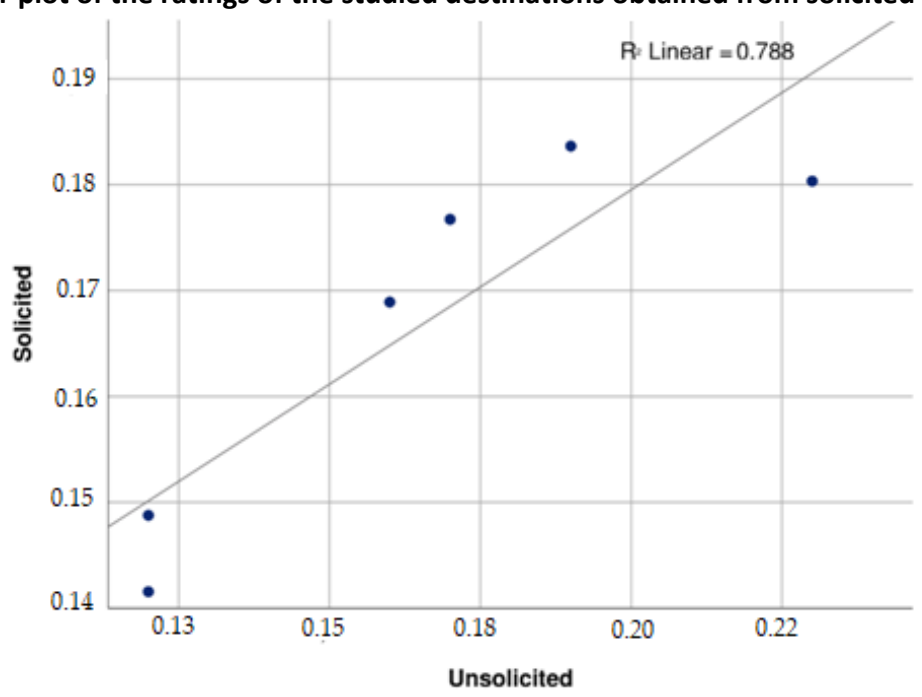

\section{Discussion and conclusion}

This article presents a novel MCDA approach to the rating tourist experience. This approach combines solicited information using direct polling and unsolicited information from opinions on social networks.

The rounded ratio of data-points obtained from solicited vs unsolicited information was 19:100. This ratio suggests that it is easier to acquire information on the experience of visitors to selected rural destinations using social network sources, even though the survey was conducted during a 3-month period covering most of the summer season in Spain.
The experimental results show a strong correlation between the solicited and unsolicited ratings of the most visited rural destinations in Málaga Province, Spain (Spearman's rho $=0.928$, $p=0.008$; linear regression coefficient $R^{2}=0.788$ ). These results suggest that the proposed MCDA approach can extract preference information from unsolicited communications. This information is strongly associated with the results of direct surveys.

However, this study only evaluated the usability of the proposed MCDA model within the context of a selected group of rural destinations in Spain. There are clear difficulties in conducting direct surveys in such areas. Therefore, future 
research in this area could consider the inclusion of urban destinations, concerning which there is a more balanced ratio of solicited vs unsolicited data-points. Also, the use of large samples and study periods referring to different seasons of the year.

This study provides important contributions to the literature on tourist experience. Firstly, it overcame some of the limitations of prior studies by considering a novel model for preferenceextraction from solicited and unsolicited data. Secondly, it presented empirical evidence using a multiple criteria decision analysis. Third, the results of this study suggest that the proposed MCDA approach can significantly reduce the number of polls required to accurately assess the preferences of visitors of rural destinations, given the difficulties in conducting direct surveys in such areas. From an applied perspective, this research shows implications for helping tourism researchers to manage large datasets of comments from different online communities.

\section{References}

Andriotis, K., Agiomirgianakis, G., \& Mihiotis, A. (2008). Measuring tourist satisfaction: A factor-cluster segmentation approach. Journal of Vacation Marketing, 14(3), 221-235. https://doi.org/10.1177/1356766708090584

Ayeh, J. K., Au, N., \& Law, R. (2013). “Do We Believe in TripAdvisor?” Examining Credibility Perceptions and Online Travelers' Attitude toward Using User-Generated Content. Journal of Travel Research, 52(4), 437452. https://doi.org/10.1177/0047287512475217

Batrinca, B., \& Treleaven, P. C. (2014). Social media analytics: a survey of techniques, tools and platforms. Al and Society, 30(1), 89-116. https://doi.org/10.1007/s00146-014-0549-4

Boley, B. B., Jordan, E. J., Kline, C., \& Knollenberg, W. (2018). Social return and intent to travel. Tourism Management, 64, 119-128. https://doi.org/10.1016/j.tourman.2017.08.008

Brown, C. B. (2015). Tourism, crime and risk perception: An examination of broadcast media's framing of negative Aruban sentiment in the Natalee Holloway case and its impact on tourism demand. Tourism Management Perspectives, 16, 266-277. https://doi.org/10.1016/J.TMP.2014.12.001

Fan, W., \& Gordon, M. D. (2013). Unveiling the Power of Social Media Analytics. Communications of the ACM, 12(JUNE 2014), 1-26. https://doi.org/10.1145/2602574

Fernández, M. A., Bendodo, E., Sánchez, J. R., \& Cabrera, F. E. (2017). A group decision process based on expert analysis and criteria coalition to measure municipalities' financial distress. Soft Computing, 1-19. https://doi.org/10.1007/s00500-017-2991-y

Kelliher, F., Reinl, L., Johnson, T. G., \& Joppe, M. (2018). The role of trust in building rural tourism micro firm network engagement: A multi-case study. Tourism Management, 68, 1-12. https://doi.org/10.1016/J.TOURMAN.2018.02.014

La Red, D. L., Doña, J. M., Peláez, J. I., \& Fernández, E. B. (2011). WKCOWA, a new Neat-OWA Operator to Aggregate Information in Democratic Decision Problems. International Journal of Uncertainty, Fuzziness and Knowledge-Based Systems, 19(05), 759-779. https://doi.org/10.1142/S0218488511007222

Liu, L., \& Liang, H. (2016). Influence analysis for celebrities via public cloud and social platform. China Communications, 13(8), 53-62. https://doi.org/10.1109/CC.2016.7563688

Liutikas, D. (2017). The manifestation of values and identity in traveling: The social engagement of pilgrimage. Tourism Management Perspectives, 24, 217-224. https://doi.org/10.1016/J.TMP.2017.07.014
Monterrubio, C. (2017). Protests and tourism crises: A social movement approach to causality. Tourism Management Perspectives, 22, 82-89. https://doi.org/10.1016/J.TMP.2017.03.001

Munar, A. M., \& Jacobsen, J. K. S. (2014). Motivations for sharing tourism experiences through social media. Tourism Management, 43, 46-54. https://doi.org/10.1016/j.tourman.2014.01.012

Ordenes, F. V., Ludwig, S., De Ruyter, K., Grewal, D., \& Wetzels, M. (2017). Unveiling What Is Written in the Stars: Analyzing Explicit, Implicit and Discourse Patterns of Sentiment in Social Media. Journal of Consumer Research, 43(6), ucw070. https://doi.org/10.1093/jcr/ucw070

Otte, E., \& Rousseau, R. (2002). Social network analysis: a powerful strategy, also for the information sciences. Journal of Information Science, 28(6), 441-453. https://doi.org/10.1177/016555150202800601

Peláez, J. I., Cabrera, F. E., \& Vargas, L. G. (2018). Estimating the relevance of consumer purchasing criteria in digital ecosystems. Knowledge-Based Systems. https://doi.org/10.1016/J.KNOSYS.2018.07.023

Rai, A., Minsker, B., Diesner, J., Karahalios, K., \& Sun, Y. (2018). Identification of Landscape Preferences by Using Social Media Analysis. In 2018 International Workshop on Social Sensing (SocialSens) (pp. 4449). IEEE. https://doi.org/10.1109/SocialSens.2018.00021

Sandberg, L., Jaradat, S., \& Dokoohaki, N. (2016). The social media election agenda: Issue salience on Twitter during the European and Swedish 2014 elections. In 2016 IEEE/ACM International Conference on Advances in Social Networks Analysis and Mining (ASONAM) (pp. 793794). IEEE. https://doi.org/10.1109/ASONAM.2016.7752328

Schroeder, A., Pennington-Gray, L., Kim, H., \& Liu-Lastres, B. (2018). Using the media's tweets to broaden previous conceptualizations of political travel risks. Tourism Management Perspectives, 26, 107-117. https://doi.org/10.1016/J.TMP.2018.03.001

Turismo y Planificación Costa del Sol S.L.U. (2017). Observatorio Turístico de la Costa del Sol 2017. Málaga.

Vagias, W. M. (2006). Likert-type scale response anchors. Clemson International Institute for Tourism \& Research Development, Department of Parks, Recreation and Tourism Management. Clemson University.

Vargas, L. G. (2016). Voting with intensity of preferences. International Journal of Information Technology \& Decision Making, 15(4), 839-859. https://doi.org/10.1142/S0219622016400058

Xiang, Z., Du, Q., Ma, Y., \& Fan, W. (2017). A comparative analysis of major online review platforms: Implications for social media analytics in hospitality and tourism. Tourism Management, 58, 51-65. https://doi.org/10.1016/j.tourman.2016.10.001

Zatori, A., Smith, M. K., \& Puczko, L. (2018). Experience-involvement, memorability and authenticity: The service provider's effect on tourist experience. Tourism Management, 67, 111-126. https://doi.org/10.1016/J.TOURMAN.2017.12.013

Zeng, B., \& Gerritsen, R. (2014). What do we know about social media in tourism? A review. Tourism Management Perspectives, 10, 27-36. https://doi.org/10.1016/J.TMP.2014.01.001

Received: 15.02 .2020

Revisions required: 12.04 .2020

Accepted: 13.06.2020 